\title{
電氣による魚肉の者熟脫 水
}

\author{
橋本鶴 夫

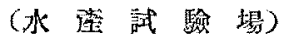

Coocking of Fish Meat by Joule's Heat.

T. HASHIMOTO

SYNOPSIS

Cooking of fish meat by Joule's heat was studied by applying alternating current of $50^{\circ} \sim$ 200 volt to fish meat in a pessing cage. Pressure on the fish meat was kept at $0.01 \sim 0.05$ $\mathrm{kg} / \mathrm{cm}^{2}$. Empirical formula for the relation between the specific resistance of fish meat and temperature during cooking, the time required for cooking and the quantity of water squeezed out of meat during cooking were obtained.

食用魚粉の暂浩工程中に於け

る意熟を簡易に行5方沠として， 魚肉に電流を通じジュール熱に 上る魚肉の惹熟並にそれに汼5

瞈水炕つき実騟を行つた。

实䲆裝置 (第1図)

木製紟胴の中に材料を入九，

その上下酒面に電榿板を置き，

交流電压 100 volt を加之る。

上部電極板上には $0.01 \sim 0.05$

$\mathrm{kg} / \mathrm{cm}^{2}$ の圧力に相当寸る整荷

重学附寸。

实路 結 果

(I) 加電中に於忛る材楼の

比抵抗

$S=$ 䍃胴の切口面皘

$h=$ 締胴中に於ける材粗の高さ

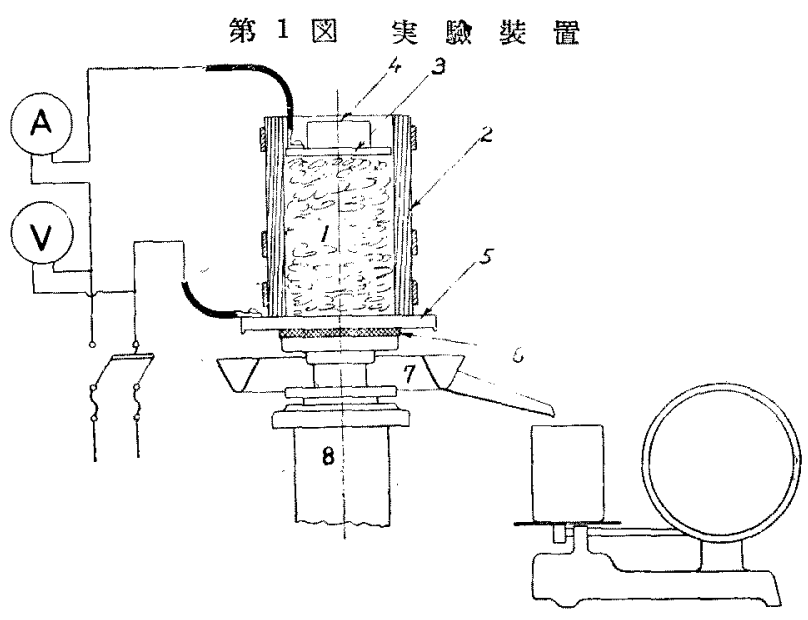

$W_{0}, W=$ 最初及ひ時間 $t$ k於け

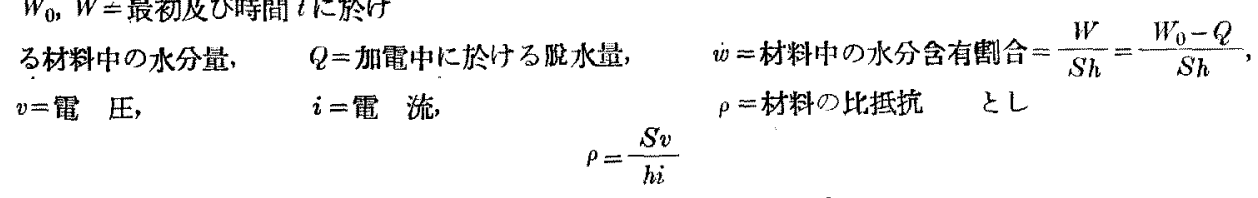

として求めた比提抗 $\rho$ と溫度 $\theta$ との䦭倸は第 2 図に示士如くである。

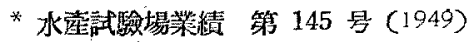

(昭和 25 年 5 月 2 日受理)

1. 試 料 (Fish Meat)

3. 上部電樰板 (Upper Plate)

5. 下部雷值板 (Lower Plate)

7. 液 受 (Receiver)

2. 編胿(木槛) (Pressing Cage)

4. 靇錘 (Weight)

6. 雷㴋程緣板 (Insulater)

8. 水压 器 (Hydraulic Press) 
第 2 図

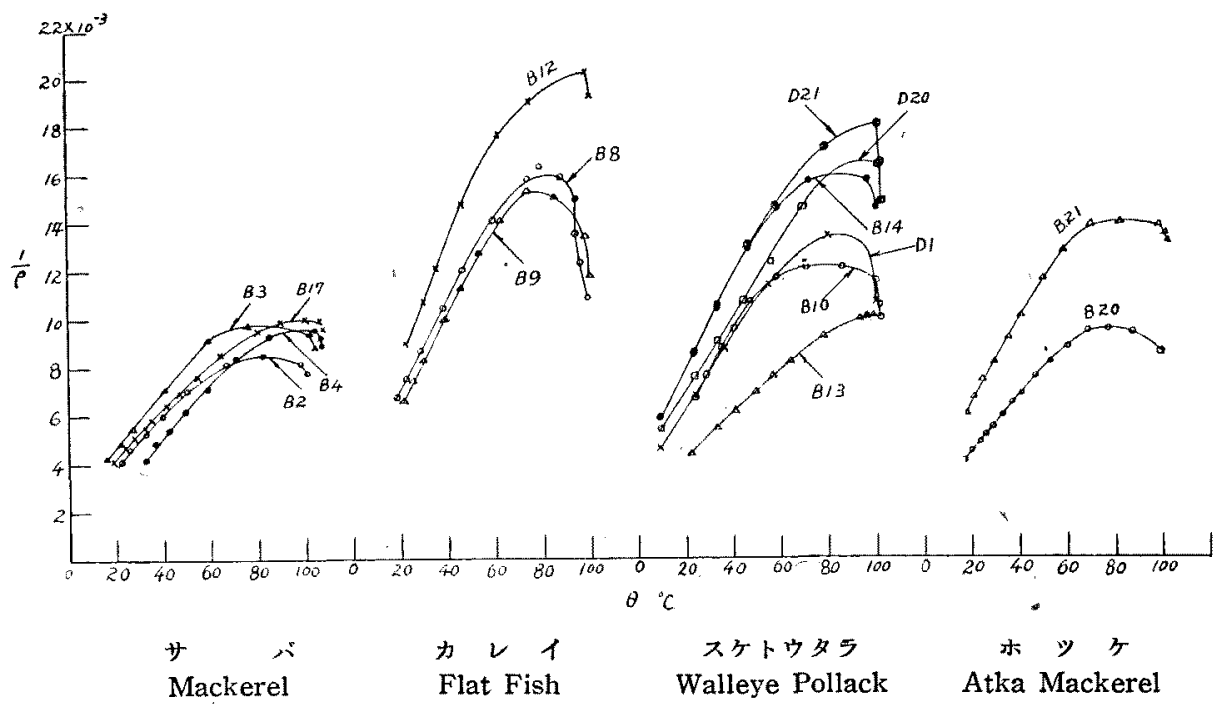

湆熟脫水の始まるまでは $\frac{1}{\rho}$ は温度と共に直線的に上昇与る。脫水の始まつた後は含有水分割合wの減 少により $\frac{1}{\rho}$ の溫度による场加率は娍じ $100^{\circ} \mathrm{C}$ 近くになり，材料內部に蒸発の起るに至り $\frac{1}{\rho}$ は急娍寸 る.

実稌結果に上り加電中の魚肉の比抵抗を次の如き実瞼式に表わし得る。

$$
\frac{1}{\rho}=(a+b \theta)\left(f \frac{w}{w_{0}}-g\right)
$$

第 1 表 Table 1.

\begin{tabular}{|c|c|c|c|c|c|c|c|c|c|}
\hline $\begin{array}{l}\text { 魚 } \text { 種 } \\
\text { Kind Fish }\end{array}$ & $\begin{array}{l}\text { 婁驗番号 } \\
\text { Expt. No. }\end{array}$ & $a$ & $b$ & $f$ & 9 & $\begin{array}{c}v \\
\text { volt }\end{array}$ & $\begin{array}{c}\dot{P} \\
\mathrm{~kg} / \mathrm{cm}^{2}\end{array}$ & $\begin{array}{l}G \\
\mathrm{~kg}\end{array}$ & $\begin{array}{l}\text { 临 } \\
\text { Remarks }\end{array}$ \\
\hline$\stackrel{+}{\text { Mackerel }}$ & $\begin{array}{r}\mathrm{B}-2 \\
3 \\
4 \\
17\end{array}$ & $\begin{array}{l}1.8 \times 10^{-3} \\
2.4 \\
0.5 \\
2.1\end{array}$ & $\begin{array}{l}0.106 \times 10 \\
0.116 \\
0.114 \\
0.102\end{array}$ & $\begin{array}{l}2.3 \\
1.9 \\
1.9 \\
1.0\end{array}$ & $\begin{array}{l}1.3 \\
0.9 \\
0.9 \\
0\end{array}$ & $\begin{array}{r}98.3 \\
103.8 \\
95.0 \\
95.5\end{array}$ & $\begin{array}{l}0.05 \\
0.05 \\
0.05 \\
0.01\end{array}$ & $\begin{array}{l}3.5 \\
3.5 \\
3.5 \\
4\end{array}$ & \\
\hline $\begin{array}{l}\Rightarrow \\
\text { Flat Fish }\end{array}$ & $\begin{array}{r}\mathrm{B}-8 \\
9 \\
12\end{array}$ & $\begin{array}{l}3.2 \\
2.5 \\
3.2\end{array}$ & $\begin{array}{l}0.192 \\
0.190 \\
0.256\end{array}$ & $\begin{array}{l}1.9 \\
2.0 \\
3.5\end{array}$ & $\begin{array}{l}0.9 \\
1.0 \\
2.5\end{array}$ & $\begin{array}{r}96.5 \\
97.0 \\
102.0\end{array}$ & $\begin{array}{l}0.05 \\
0.01 \\
0.01\end{array}$ & $\begin{array}{l}4 \\
4 \\
4\end{array}$ & $\begin{array}{l}\mathrm{B}-12 \text { 沬 } \\
\text { 塩水漫 } \\
\text { Sipped in } \\
\text { Salt Water }\end{array}$ \\
\hline $\begin{array}{c}\text { スケウウ } \\
\text { タラ } \\
\text { Walleye } \\
\text { Pollack }\end{array}$ & $\begin{array}{r}\mathrm{B}-10 \\
13 \\
14 \\
\mathrm{D}-1 \\
20 \\
21\end{array}$ & $\begin{array}{l}2.8 \\
2.4 \\
4.2 \\
3.1 \\
4.0 \\
4.0\end{array}$ & $\begin{array}{l}0.155 \\
0.095 \\
0.188 \\
0.152 \\
0.154 \\
0.192\end{array}$ & $\begin{array}{l}2.3 \\
1.0 \\
2.8 \\
1.9 \\
-\end{array}$ & $\begin{array}{l}1.3 \\
0 \\
1.8 \\
0.9 \\
=\end{array}$ & $\begin{array}{r}100.0 \\
97.1 \\
98.8 \\
96.1 \\
101.4 \\
100.4\end{array}$ & $\begin{array}{l}0.01 \\
0.01 \\
0.01 \\
0.01 \\
0.01 \\
0.05\end{array}$ & $\begin{array}{l}4 \\
3 \\
3 \\
1 \\
1 \\
1\end{array}$ & $\begin{array}{l}\text { B-14 } \\
\text { 壏水浸 婊 } \\
\text { Dipped in } \\
\text { Salt Water }\end{array}$ \\
\hline $\begin{array}{c}\text { ホッ } \\
\text { Atka } \\
\text { Mackerel }\end{array}$ & $\begin{array}{r}B-20 \\
21\end{array}$ & $\begin{array}{l}1.95 \\
3.0\end{array}$ & $\begin{array}{l}0.122 \\
0.174\end{array}$ & $\begin{array}{l}3.6 \\
3.6\end{array}$ & $\begin{array}{l}2.6 \\
2.6\end{array}$ & $\begin{array}{r}99.7 \\
102.5\end{array}$ & $\begin{array}{l}0.02 \\
0.02\end{array}$ & $\begin{array}{l}4 \\
4\end{array}$ & $\begin{array}{l}\mathrm{B}-21 \text { } \\
\text { 顜水浸洼 } \\
\text { Sipped in } \\
\text { Salt Water }\end{array}$ \\
\hline
\end{tabular}




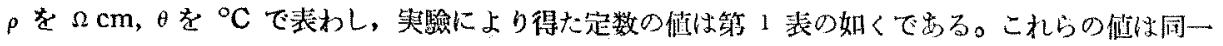

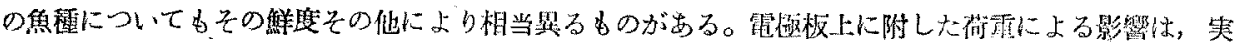
驗に探用した $0.01 〜 0.05 \mathrm{~kg} / \mathrm{cm}^{2}$ の程䏠では殖儿ど見られなな。

(II) 温度の上昇

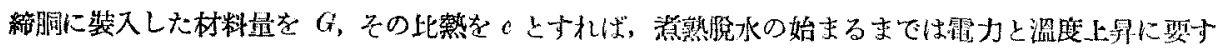
る烝量との閶係は

$$
J \text { vid } t=c G d \theta \quad \text { 但し } J \text { は霣力の憼当量 }
$$

或は,$\frac{J v^{2} S}{h}(a+b \theta) d t=c G d \theta$

脫水の始まるまでは $h$ は殆儿ど不変で最初の値 $h_{0}$ に等しく， 又 $\boldsymbol{c}$ を一定とみなし，且つ

$$
\begin{array}{lr}
a=\frac{J v^{2} S b}{h_{0} e G} & \text { と怙けば上式から } \\
\theta=A e^{a_{t}-B} & \quad(1) \\
A=\frac{a+b \theta_{0}}{b} . & B=\frac{a}{b}
\end{array}
$$

但L

を得る。

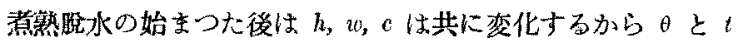

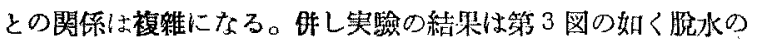
始まつた後も矢張り大体（1）式により表わされる指数曲線の延 長となつて表わされる。故に溫度と時間との哭係性熱熱䆓水の 前後を通して同一の式(1)を以て表わ蚁れるものとい方る。

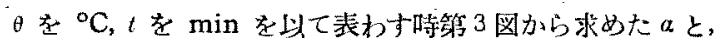

\begin{tabular}{|c|c|c|c|c|c|}
\hline $\begin{array}{l}\text { 魚 } \\
\text { Kind of Fish }\end{array}$ & $\begin{array}{l}\text { 実驗雨号 } \\
\text { Expt. } \\
\text { No. }\end{array}$ & $\alpha$ & $\alpha_{0}$ & $G \mathrm{~kg}$ & 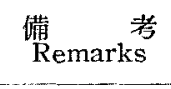 \\
\hline $\begin{array}{l}\text { サackerel } \\
\text { Má }\end{array}$ & $\begin{array}{r}\mathrm{B}-2 \\
3 \\
4 \\
17 \\
\end{array}$ & $\begin{array}{l}0.045 \\
0.058 \\
0.060 \\
0.035\end{array}$ & $\begin{array}{l}0.045 \\
0.061 \\
0.049 \\
0.028 \\
\end{array}$ & $\begin{array}{l}3.5 \\
3.5 \\
3.5 \\
4\end{array}$ & \\
\hline $\begin{array}{l}\text { カ } \\
\text { Flat Fish }\end{array}$ & $\begin{array}{r}B-8 \\
9 \\
12\end{array}$ & $\begin{array}{l}0.068 \\
0.050 \\
0.081\end{array}$ & $\begin{array}{l}0.070 \\
0.060 \\
0.084\end{array}$ & $\begin{array}{l}4 \\
4 \\
4\end{array}$ & $\begin{array}{l}\mathrm{B}-12 \text { 缸水浸 清 } \\
\text { Dipped in } \\
\text { Salt Water }\end{array}$ \\
\hline $\begin{array}{c}\text { スケトウ } \\
\text { タ ラ } \\
\text { Walleye } \\
\text { Pollack }\end{array}$ & $\begin{array}{r}\mathrm{B}-10 \\
13 \\
14 \\
\mathrm{D}-1 \\
20 \\
.21\end{array}$ & $\begin{array}{l}0.052 \\
0.054 \\
0.093 \\
0.136 \\
0.160 \\
0.198\end{array}$ & $\begin{array}{l}0.035 \\
0.049 \\
0.101 \\
0.166 \\
0.187 \\
0.240\end{array}$ & $\begin{array}{l}4 \\
3 \\
3 \\
1 \\
1 \\
1\end{array}$ & $\begin{array}{l}\text { 培水浸 清 } \\
\text { Dipped in } \\
\text { Salt Water }\end{array}$ \\
\hline $\begin{array}{c}\text { * }{ }^{*} \text { Atka } \\
\text { Mackerel }\end{array}$ & $\begin{array}{r}B-20 \\
20\end{array}$ & $\begin{array}{l}0.032 \\
0.051\end{array}$ & $\begin{array}{l}0.037 \\
0.056\end{array}$ & $\begin{array}{l}4 \\
4\end{array}$ & $\begin{array}{l}\mathrm{B}-21 \text { } \\
\text { 筑水 清 清 } \\
\text { Dipped in } \\
\text { Salt Water }\end{array}$ \\
\hline
\end{tabular}

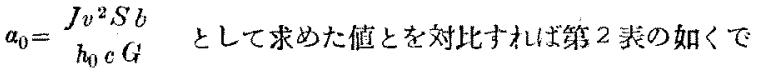
ある。

$$
\text { 第 } 2 \text { 表 Table } 2 .
$$

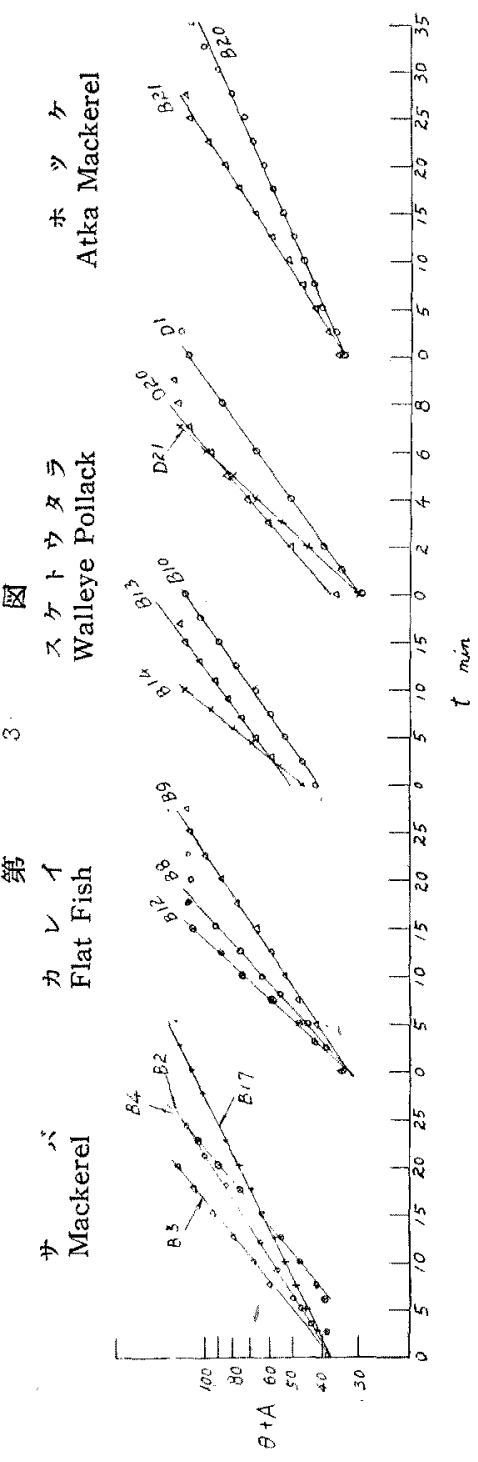


518

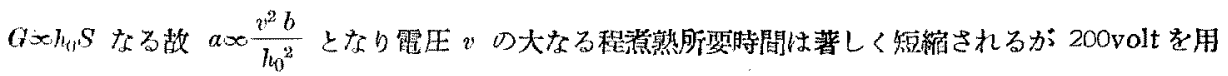

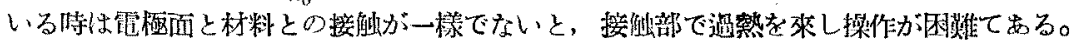

材料走予め塩水に浸清しておいたすのは $b$ が大なる故所瑟時間は短縮される。

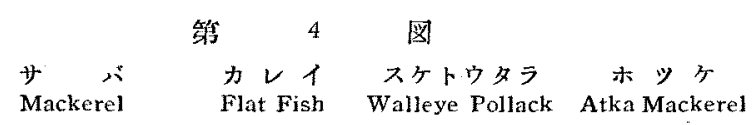

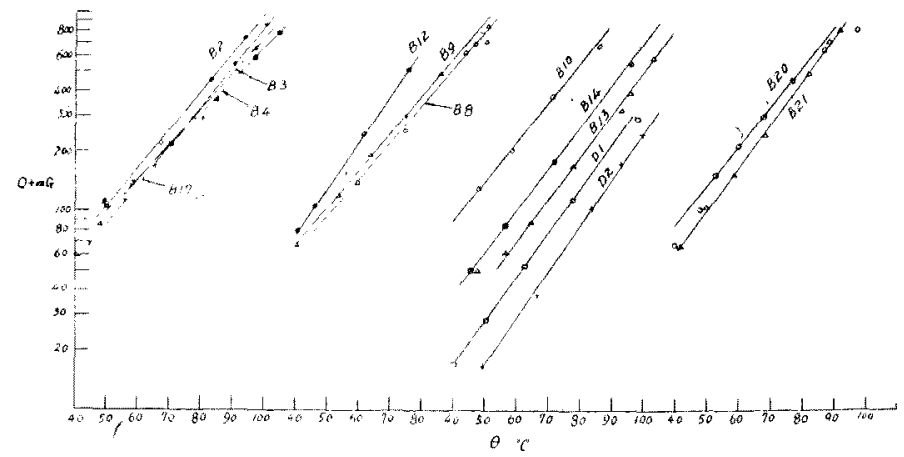

第 3 㤗 Table 3.

\begin{tabular}{|c|c|c|c|c|c|}
\hline Kind of Fish & 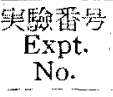 & $\beta$ & $\begin{array}{c}G \\
\mathrm{~kg}\end{array}$ & $\underset{\mathrm{kg} / \mathrm{cm}^{2}}{P}$ & $\begin{array}{c}\text { 傃 } \\
\text { Remarks }\end{array}$ \\
\hline Mackeré & $\begin{array}{r}\mathrm{B}-2 \\
3 \\
4 \\
17\end{array}$ & $\begin{array}{l}0.044 \\
0.042 \\
0.039 \\
0.046\end{array}$ & $\begin{array}{l}3.5 \\
3.5 \\
3.5 \\
4\end{array}$ & $\begin{array}{l}0.05 \\
0.05 \\
0.05 \\
0.01\end{array}$ & \\
\hline Flat Fish & $\begin{array}{r}\mathrm{B}-8 \\
9 \\
12\end{array}$ & $\begin{array}{l}0.043 \\
0.043 \\
0.053\end{array}$ & $\begin{array}{l}4 \\
4 \\
4\end{array}$ & $\begin{array}{l}0.05 \\
0.01 \\
0.01\end{array}$ & $\begin{array}{l}\mathrm{B}-12 は \\
\text { 嫶 水 漫 清 } \\
\text { Dipped in } \\
\text { Salt Water }\end{array}$ \\
\hline $\begin{array}{c}\text { スケトウ } \\
\text { ダラ } \\
\text { Walleye } \\
\text { Pollack }\end{array}$ & $\begin{array}{r}\mathrm{B}-10 \\
13 \\
14 \\
\mathrm{D}-1 \\
2\end{array}$ & $\begin{array}{l}0.046 \\
0.050 \\
0.049 \\
0.050 \\
0.052\end{array}$ & $\begin{array}{l}4 \\
3 \\
3 \\
1 \\
1\end{array}$ & $\begin{array}{l}0.01 \\
0.01 \\
0.01 \\
0.01 \\
0.01\end{array}$ & $\begin{array}{l}\mathrm{B}-14 \text { } \\
\text { 埝水 浸 } \\
\text { Dipped in } \\
\text { Salt Water }\end{array}$ \\
\hline $\begin{array}{c}\text { Atka } \\
\text { Mackerel }\end{array}$ & $\begin{array}{r}B-20 \\
21\end{array}$ & $\begin{array}{l}0.047 \\
0.051\end{array}$ & $\begin{array}{l}4 \\
4\end{array}$ & $\begin{array}{l}0.02 \\
0.02\end{array}$ & 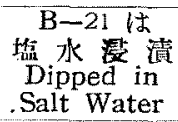 \\
\hline
\end{tabular}

(III) 腹 水 量

温度が上萫するに件い㵭熟は促進 せられ，従つて脫水量を增与。膯水

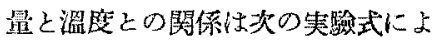
る指数曲線を以て践わされる。

$$
Q=m G\left\{e^{\beta\left(\theta-\theta_{1}\right)}-1\right\}
$$

但し $\theta_{1}$ は境㷫の始末る溫度であ つて, 実驗結果からみると大体 $\theta_{1}=$ 40〜 45 $5^{\circ}$ のよ5である。定数 $m$ の 健化大体 0.017 でり,この值をと り $Q$ と $\theta$ との网係を圂示才ると第 4 図の如く，これから $\beta$ の值を求め るとその值は第 3 表の如くでかる。

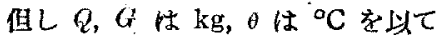
表わ寸るのとする。

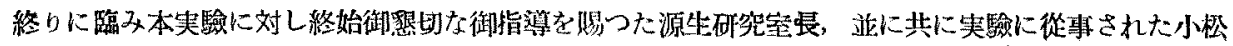

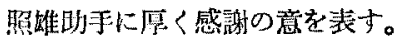

